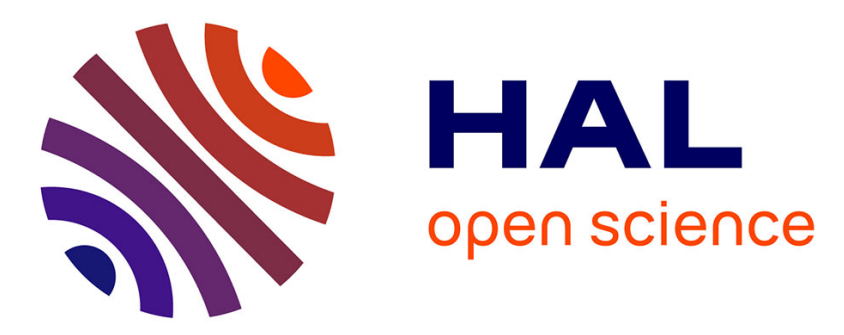

\title{
Implementation of trastuzumab in conjunction with adjuvant chemotherapy in the treatment of non-metastatic breast cancer in the Netherlands
}

L. Munck, M. Schaapveld, S. Siesling, J. Wesseling, A. C. Voogd, V. C. G. Tjan-Heijnen, R. Otter, P. H. B. Willemse

\section{To cite this version:}

L. Munck, M. Schaapveld, S. Siesling, J. Wesseling, A. C. Voogd, et al.. Implementation of trastuzumab in conjunction with adjuvant chemotherapy in the treatment of non-metastatic breast cancer in the Netherlands. Breast Cancer Research and Treatment, 2011, 129 (1), pp.229-233. 10.1007/s10549-011-1451-0 . hal-00626241

\section{HAL Id: hal-00626241 \\ https://hal.science/hal-00626241}

Submitted on 24 Sep 2011

HAL is a multi-disciplinary open access archive for the deposit and dissemination of scientific research documents, whether they are published or not. The documents may come from teaching and research institutions in France or abroad, or from public or private research centers.
L'archive ouverte pluridisciplinaire HAL, est destinée au dépôt et à la diffusion de documents scientifiques de niveau recherche, publiés ou non, émanant des établissements d'enseignement et de recherche français ou étrangers, des laboratoires publics ou privés. 
Implementation of trastuzumab in conjunction with adjuvant chemotherapy in the treatment of non-metastatic breast cancer in The Netherlands

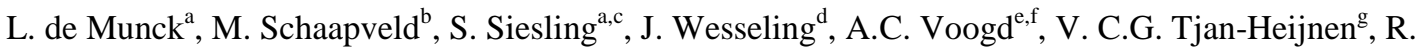
Otter $^{\text {h }}$, P.H.B. Willemse ${ }^{\mathrm{i}}$

${ }^{a}$ Department of Research, Comprehensive Cancer Centre North East, P.O. Box 330, 9700 AH Groningen, The Netherlands

${ }^{\mathrm{b}}$ Department of Psychosocial Research and Epidemiology, The Netherlands Cancer Institute - Antoni van Leeuwenhoek Hospital, Plesmanlaan 121, 1066 CX Amsterdam, The Netherlands

${ }^{c}$ Department of Health Technology \& Services Research, University of Twente, P.O. Box 217, 7500 AE Enschede, The Netherlands

${ }^{\mathrm{d}}$ Department of Pathology, The Netherlands Cancer Institute - Antoni van Leeuwenhoek Hospital, Plesmanlaan 121, 1066 CX Amsterdam, The Netherlands

${ }^{\mathrm{e}}$ Department of Epidemiology, GROW - School for Oncology and Developmental Biology, Maastricht University Medical Centre, P.O. Box 5800, 6202 AZ Maastricht, The Netherlands

${ }^{\mathrm{f}}$ Department of Research, Comprehensive Cancer Centre South (CCCS), P.O. Box 231, 5600 AE Eindhoven, The Netherlands

${ }^{\mathrm{g}}$ Division of Medical Oncology, Department of Internal Medicine, GROW - School for Oncology and Developmental Biology, Maastricht University Medical Centre, P.O. Box 5800, 6202 AZ Maastricht, The Netherlands

${ }^{\mathrm{h}}$ Director, Comprehensive Cancer Centre North East, P.O. Box 330, 9700 AH Groningen, The

Netherlands

${ }^{\text {i }}$ Department of Medical Oncology, University Medical Centre Groningen, P.O. Box 30001, 9700 RB

Groningen, The Netherlands

Corresponding author:

L. de Munck

P.O. Box 330

9700 AH Groningen, The Netherlands 
Tel: $+31(0) 882345500$

Fax: +31 (0) 882345599

E-mail: 1.demunck@ikno.nl

L. de Munck $\quad 1$ 
Abstract

Background.

Trastuzumab in conjunction with adjuvant chemotherapy markedly improves outcome. In the Netherlands, a national guideline was released in September 2005 stating that trastuzumab should be given in conjunction with adjuvant chemotherapy in women with HER2 positive breast cancer. Aim of this study was to identify the number of women with HER2-positive breast cancer and to evaluate the level of implementation of adjuvant trastuzumab in clinical practice nationwide.

Patients and methods.

Women diagnosed with primary breast cancer between September 2005 - January 2007 were selected from the Netherlands Cancer Registry (NCR). HER2 status, adjuvant treatment and reasons to withhold trastuzumab were registered.

Results.

14,934 Breast cancer patients were diagnosed in this period of whom 1,928 (13\%) had a HER2-positive tumour. Of all HER2-positive women receiving adjuvant chemotherapy, $66(6 \%)$ did not receive trastuzumab. This percentage decreased from $10 \%$ at the time of introduction of the guideline to $4 \%$ in the study period September 2005 December 2006. Most common reasons to withhold trastuzumab were cardiovascular disease (29\%) and patient refusal $(21 \%)$.

Conclusion.

Of all HER2-positive patients who received adjuvant chemotherapy, 94\% received trastuzumab. The implementation of trastuzumab in clinical practice was realized within 8 months after introduction of the new guideline.

Keywords: adjuvant, breast cancer, guideline, HER2, trastuzumab, 


\section{Introduction}

Breast cancer is the most common cancer in women in the Netherlands, accounting for about one third of all female cancers [1]. Approximately $10-25 \%$ of breast cancers have overexpression of the human epidermal growth factor receptor 2 (HER2) protein and/or amplification of the HER2 gene [2-5]. In May 2005 the results of three large randomised studies were presented, revealing that in women with HER2-positive breast cancer, the risk of developing recurrences or distant metastases and the risk of death decreased by more than $30 \%$ by adding one year adjuvant treatment with trastuzumab [6,7]. Based on these results, recommendations for HER2-testing and the use of adjuvant trastuzumab were rapidly included in national and international guidelines [8].

The aim of this study was to evaluate the level of implementation of the Dutch guidelines for HER2-testing and the use of trastuzumab in clinical practice, analysing regional differences and reasons for withholding trastuzumab. 


\section{Patients and Methods}

\section{Patients}

Patients were selected from the population-based Netherlands Cancer Registry (NCR) of the Association of Comprehensive Cancer Centres (CCCs) in the Netherlands, covering all 16 million inhabitants. The Association of CCCs consisted of 9 regional CCCs, which support the development and implementation of national guidelines by means of multidisciplinary working groups and consultancy services (on local, regional and national level), and monitor guideline compliance after their implementation using Cancer Registry data.

Main source of notification for the NCR is PALGA, the nationwide Dutch network and registry of histo- and cytological pathology, through which all newly diagnosed malignancies are reported to the cancer registry. Case ascertainment is completed by using the national hospital discharge database, which receives the diagnosis of admitted patients from all hospitals. After notification to the NCR, specially trained registrars of the CCCs visit the hospitals to collect information on patient and tumour characteristics, stage and treatment from patient files. Coding of the items is based on international coding rules (IACR). TNM classification was used for the staging of tumours [9]. Since 2005 HER2 status was recorded in the NCR on a routine basis. HER2-positivity was defined using a widely recommended testing algorithm [10,11]. An immunohistochemistry (IHC) score 3+ was considered positive. When IHC was inconclusive (2+), an additional fluorescent in situ hybridization (FISH) test was indicated. IHC score 3+ or a positive FISH test was considered indicative for HER2-positivity. All women diagnosed with invasive breast cancer between September 2005 and January 2007 were selected $(\mathrm{n}=17,781)$. Women without surgery or with metastases at diagnosis, and women who received neo-adjuvant chemotherapy were excluded from analysis, leaving 14,934 women for analysis in this study.

\section{Treatment guidelines}

In the Netherlands, guidelines are developed by the National Breast Cancer Organization of The Netherlands (NABON). They released the adapted national guideline in September 2005 indicating that for women with HER2positive breast cancer trastuzumab should be given in conjunction with adjuvant chemotherapy. If women with HER2-positive tumours and chemotherapy did not receive adjuvant trastuzumab, reasons to withhold trastuzumab were documented by the registrars from the CCCs.

\section{Statistical analysis}

Time of diagnosis was divided into 4 periods of 4 months. Regions in the Netherlands were defined according to the areas covered by the 9 CCCs [1]. Logistic regression was performed to study differences in the use of trastuzumab between regions. The region with the highest use of trastuzumab was coded as reference. Age (10-year categories) 
and tumour stage (stage I, II and III) were included as covariates. The statistical significance level was set at a pvalue $<0.05$. Analyses were performed using the STATA software package, version 10.1 for Windows (Stata Corporation LP, College Station, TX, USA). 


\section{Results}

HER2 status

Between September 2005 and January 2007 14,934 women with invasive breast cancer were included in the study. Median age at diagnosis was 60 years (range 21-101, Table 1). Of these, 1,928 (13\%) women were diagnosed with HER2-positive breast cancer. The percentage of HER2-positive tumours decreased with increasing age from $22 \%$ in women younger than 40 years to $10 \%$ in women 70 years or older (Figure $1, \mathrm{p}<0.001$ ). In $4 \%$ of women under 40 years of age HER2-status was unknown or not tested. This percentage increased to $8 \%$ in women over 70 (Figure 2). Both the percentage HER2-positive tumours (range 11\%-15\%, p=0.008) and the percentage with HER2-status unknown or not tested (range 3\%-13\%,p<0.001) varied between the CCC regions.

\section{Use of trastuzumab}

Of all 1,928 women with HER2-positive breast cancer, 1,114 (58\%) received adjuvant chemotherapy. This percentage decreased from $93 \%$ among women $<40$ years to $6 \%$ among women over 70 years of age (Figure 3 ). Of the 1,114 women with HER2-positive breast cancer who received adjuvant chemotherapy, 1,058 (94\%) patients did receive trastuzumab as well. Only $6 \%$ (66 patients) did not receive trastuzumab; this percentage increased with age from $4 \%$ in women younger than 40 years to $11 \%$ in women aged $60-69$ and varied between $3 \%$ and $16 \%$ between the CCC regions. Adjusted for age and stage there was a significant difference between CCC regions ( $\mathrm{p}=0.004)$. The Odds Ratios for the CCC regions ranged from 0.17 to 0.97 compared to the reference region.

\section{Implementation of trastuzumab}

At the time the recommendation for the use of trastuzumab was included in the national guideline (September 2005), $10 \%$ of the women with HER2 overexpression receiving adjuvant chemotherapy did not receive trastuzumab. This percentage decreased to $4 \%$ in the last study period (September-December 2006) (Figure 4, p<0.001). In the period May 2006 - December 2006 the variation between the regions in the proportion of patients receiving trastuzumab had disappeared, after adjusting for age and stage $(\mathrm{p}=0.901)$. The Odds Ratios for the CCC regions ranged from 0.32 to 1.56 compared to the reference region.

\section{Reasons to withhold trastuzumab}

The most frequently reported reasons for doctors not to give trastuzumab were a history of cardiovascular disease, patient refusal and older age. In $36 \%$ no reason to withhold trastuzumab was reported in the patient files (Table 2). 


\section{Discussion}

Of women with HER2-positve breast cancer who received adjuvant chemotherapy, 94\% actually received trastuzumab. For $64 \%$ of the women who did not receive trastuzumab, a legitimate reason was reported in the patient files. Keeping in mind that the guideline had only been made public in September 2005 and that the time period immediately after its release was also included in this study, we may conclude that the level and the speed of the implementation of trastuzumab in clinical practice was very satisfactory. The time needed to implement the new guideline in clinical practice varied between CCC regions, but within 8 months the differences between CCC regions had disappeared. These differences in time can partly be explained by different dates of meetings of the multidisciplinary working groups and consultancy services (on local, regional and national level).

In this study, population-based data from the NCR, covering the whole of the Netherlands were used. Of all included women with primary breast cancer, $13 \%$ was diagnosed with HER2-positive cancer. In a meta analysis by Dendukuri et al.[5] about $16 \%$ of primary breast cancers was HER2-positive, which is comparable to the percentage found in this study. Other studies have shown a percentage of around $25 \%[3,4,12]$. However, those were studies performed in the initial period of HER2 testing, or studies with selected groups of patients, e.g. only including metastatic breast cancer or hormone receptor negative patients. At present, the most widely accepted and well established algorithm to determine HER2 status is to start with IHC, followed by FISH when IHC proves to be inconclusive. HER2 testing was introduced in Dutch reference pathology laboratories before this guideline was issued, as trastuzumab was already common practice for the treatment of metastatic breast cancer. However, in the beginning the quality of HER2 testing varied between laboratories. A number of variables (e.g. tissue handling and fixation) can affect the accuracy of the results and comparative studies were published about the discordance rates between laboratories and tests $[10,11,13,14]$. The pathologists realised that differences in determining HER2 status existed and updated guidelines for HER2 testing were added to the national guideline [8]. Viewing the results of our study in this light, part of the differences between CCC regions could be explained by the differences in pathology laboratories.

IHC and/or FISH-tests are somewhat less often performed in the older patients. The guideline is clear about the conjunction of trastuzumab with chemotherapy in women under 70 [8]. For women above the age of 70 the guideline does not give standard advice for adjuvant chemotherapy due to insufficient data. For these women other factors (e.g. hormone sensitivity, co-morbidity and frailty) play an important role in supplying chemotherapy (and trastuzumab). Therefore, determining HER2 status is of limited relevance in this age group. 
Because this study investigated the timelines and the rate of implementation of the new guideline for the use of trastuzumab, patients with metastases or receiving neo-adjuvant chemotherapy were excluded. The use of trastuzumab is coded when treatment with trastuzumab started, but no information was gathered about its duration or if it was temporary interrupted, e.g. for cardiotoxicity. However, the aim of the current study was to study the proportion of patients starting with trastuzumab. Any premature termination of treatment for cardiotoxicity or other reasons and its impact on morbidity, recurrence and survival should be part of another study.

This study is unique because of the setting in which it has been performed. The collaboration between the National Breast Cancer Organization of The Netherlands (NABON), the CCCs and the NCR has resulted in a quality system in which the development, implementation, monitoring and evaluation of the guideline is covered as a whole. This study proves that new tumour characteristics and treatments can be registered by the NCR within reasonable time. The registry clerks of all CCCs use the same strict definitions and coding rules, which enhances the quality of the data and thus the reliability of the results.

In conclusion, our study shows that of all Dutch women with non-metastatic invasive breast cancer, $13 \%$ has HER2 overexpression and this percentage markedly decreases with age. Of the women with HER2-positive breast cancer who received adjuvant chemotherapy, $94 \%$ actually received trastuzumab. The implementation of trastuzumab in clinical practice was realized within 8 months after introduction of the new guideline. This study shows that a population-based cancer registry can be of great value when evaluating the implementation of new treatment policies.

\section{Conflict of interest statement}

None declared. 


\section{References}

1. Comprehensive Cancer Centres. <http://www.cancerregistry.nl> [accessed 8.8.2010].

2. Slamon DJ, Clark GM, Wong SG, Levin WJ, Ullrich A, McGuire WL. (1987) Human Breast Cancer: Correlation of Relapse and Survival with Amplification of the HER-2/neu. Oncogen;177-182.

3. Slamon DJ, Godolphin W, Jones LA, Holt JA, Wong SG. Keith DE, Levin WJ, Stuart SG, Udove J, Ullrich A Press MF (1989) Studies of the HER-2/neu Proto-Oncogene in Human Breast and Ovarian Cancer. Science 244:707-12.

4. Dowsett M, Bartlett J, Ellis IO, Salter J, Hills M, Mallon E, Watters AD, Cooke T, Paish C, Wencyk PM, Pinder SE (2003) Correlation between immunohistochemistry (HercepTest) and fluorescence in situ hybridization (FISH) for HER-2 in 426 breast carcinomas from 37 centres. The Journal of Pathology 199:41823.

5. Dendukuri N, Khetani K, McIsaac M, Brophy J. (2007) Testing for Her2-positive breast cancer: a systematic review and cost-effectiveness analysis. CMAJ 176:1429-34.

6. Romond EH, Perez EA, Bryant J, Suman VJ, Geyer CE, et al. (2005) Trastuzumab plus Adjuvant Chemotherapy for Operable HER2-Positive Breast Cancer. N Engl J Med 353:1673-84.

7. Piccart-Gebhart MJ, Procter M, Leyland-Jones B, Goldhirsch A, Untch M, et al. (2005) Trastuzumab after Adjuvant Chemotherapy in HER2-Positive Breast Cancer. N Engl J Med 353:1659-72.

8. National Breast Cancer Organization of The Netherlands. Guideline breast cancer. <http://www.oncoline.nl> [accessed 8.8.2010].

9. Wittekind C, Greene FL, Hutter RVP, Klimpfinger M, Sobin LH (2004) TNM Atlas, 5th edition. SpringerVerlag, Berlin

10. Bilous M, Dowsett M, Hanna W, Isola J, Lebeau A, Moreno A, Penault-Llorca F, Ruschoff J, Tomasic G, Vijver M vd (2003) Current Perspectives on HER2 Testing: A Review of National Testing Guidelines. Mod Pathol 16(2):173-82.

11. Yaziji H, Goldstein L, Barry T, Werling R, Hwang H, Ellis GK, Gralow JR, Livingston RB, Gown AM (2004) Her-2 Testing in Breast Cancer Using Parallel Tissue-Based Methods. JAMA 291:1972-7.

12. Bartlett JMS, Ellis IO, Dowsett M, Mallon EA, Cameron DA, Johnston S, Hall E, A'Hern R, Peckitt C, Bliss JM, Johnson L, Barrett-Lee P, Ellis P (2007) Human Epidermal Growth Factor Receptor 2 Status Correlates 
With Lymph Node Involvement in Patients With Estrogen Receptor (ER)-Negative, but With Grade in Those With ER-positive Early-Stage Breast Cancer Suitable for Cytotoxic Chemotherapy. J Clin Oncol 25: 4423-4430

13. Perez EA, Suman VJ, Davidson NE, Marino S, Kaufman PA, Lingle WL, Flynn PF, Ingle JN, Visscher D, Jenkins RB (2006) HER2 Testing by Local, Central, and Reference Laboratories in Specimens From the North Central Treament Group N9831 Intergroup Adjuvant Trial. J Clin Oncol 24: 3032-3038

14. Paik S, Bryant J, Tan-Chiu E, Romond E, Hiller W, Park K, Brown A, Yothers G, Anderson S, Smith R, Wickerham L, Wolmark N (2002) Real-World Performance of HER2 Testing - National Surgical Adjuvant Breast and Bowel Project Experience. J Natl Cancer Inst 94:852-854 
Table 1 - Patient characteristics

\begin{tabular}{clrr}
\hline All patients $(\mathrm{n}=14,934)$ & & $\mathrm{N}$ & $\%$ \\
\hline Age & median & 60 & \\
& range & $21-101$ & \\
& $<40$ & 785 & 5 \\
& $40-49$ & 2,806 & 19 \\
& $50-59$ & 4,006 & 27 \\
& $60-69$ & 3,599 & 24 \\
& $70-79$ & 2,448 & 16 \\
& $80+$ & 1,290 & 9 \\
\hline HER2 status & negative & 11,574 & 77 \\
(IHC and/or FISH) & IHC 2+ & 486 & 3 \\
& positive & 1,928 & 13 \\
& unknown & 946 & 6 \\
\hline HER2 positive patients $(\mathrm{n}=1,928)$ & & \\
(IHC and or FISH) & & 814 & 42 \\
\hline Chemotherapy & no & 1,114 & 58 \\
\hline Trastuzumab & yes & 1,057 & 45 \\
\hline & no & & \\
\hline & yes & & \\
\hline
\end{tabular}


Table 2 - Reasons for withholding trastuzumab $(\mathrm{n}=66)$

\begin{tabular}{lrr}
\hline & $\mathrm{N}$ & $\%$ \\
\hline Cardio toxicity & 19 & 29 \\
Patient refusal & 14 & 21 \\
Age & 7 & 11 \\
Other & 2 & 3 \\
No reason given (for withholding) & 24 & 36
\end{tabular}


Fig. 1 Percentage of patients with a HER2-positive tumour, by age, in the period September 2005 - December 2006. The vertical lines show the range between CCC regions.

Fig. 2 Percentage of patients with a HER2 status unknown or not tested, by age, in the period September 2005 December 2006. The vertical lines show the range between CCC regions.

Fig. 3 Percentage of patients with HER2-positive breast cancer receiving chemotherapy.

Fig. 4 Percentage of patients with HER2-positive tumours and adjuvant chemotherapy, receiving trastuzumab, by period. The symbols represent the different CCC regions.

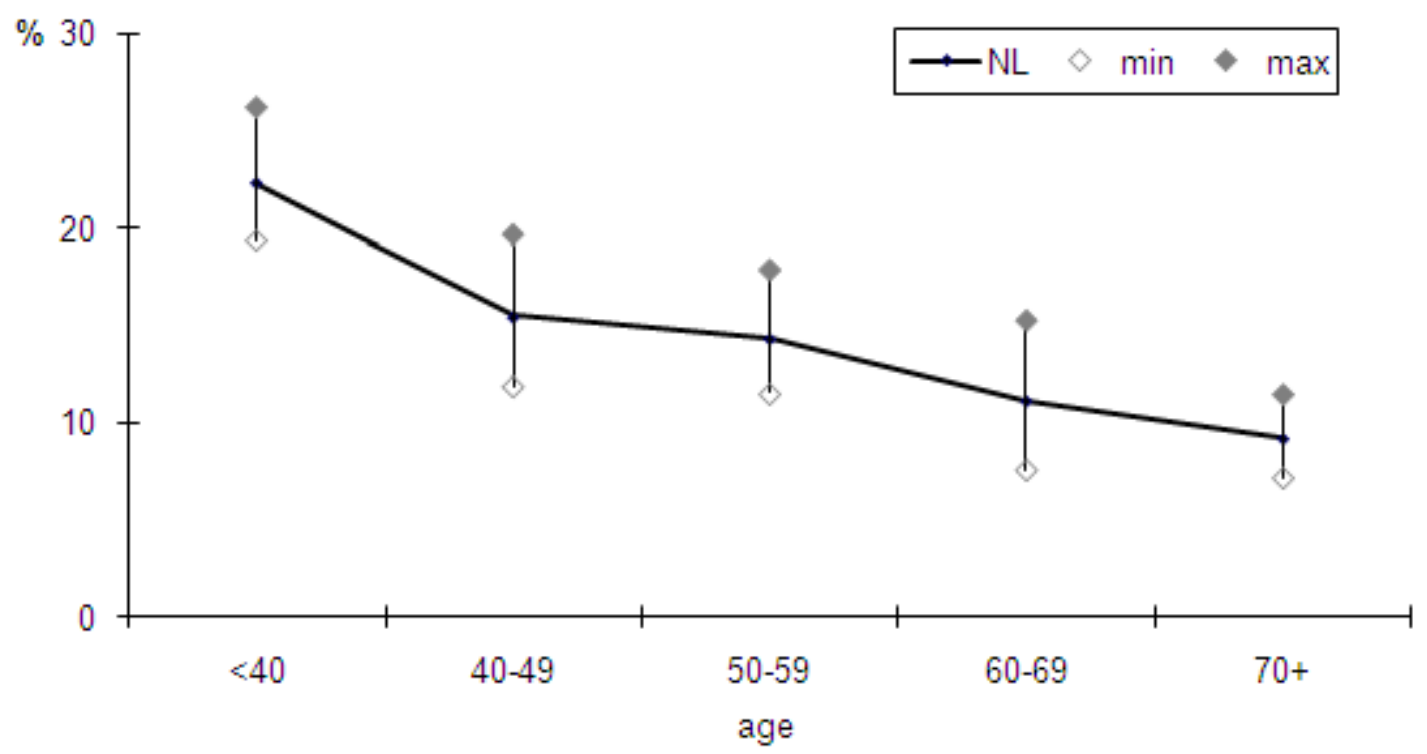



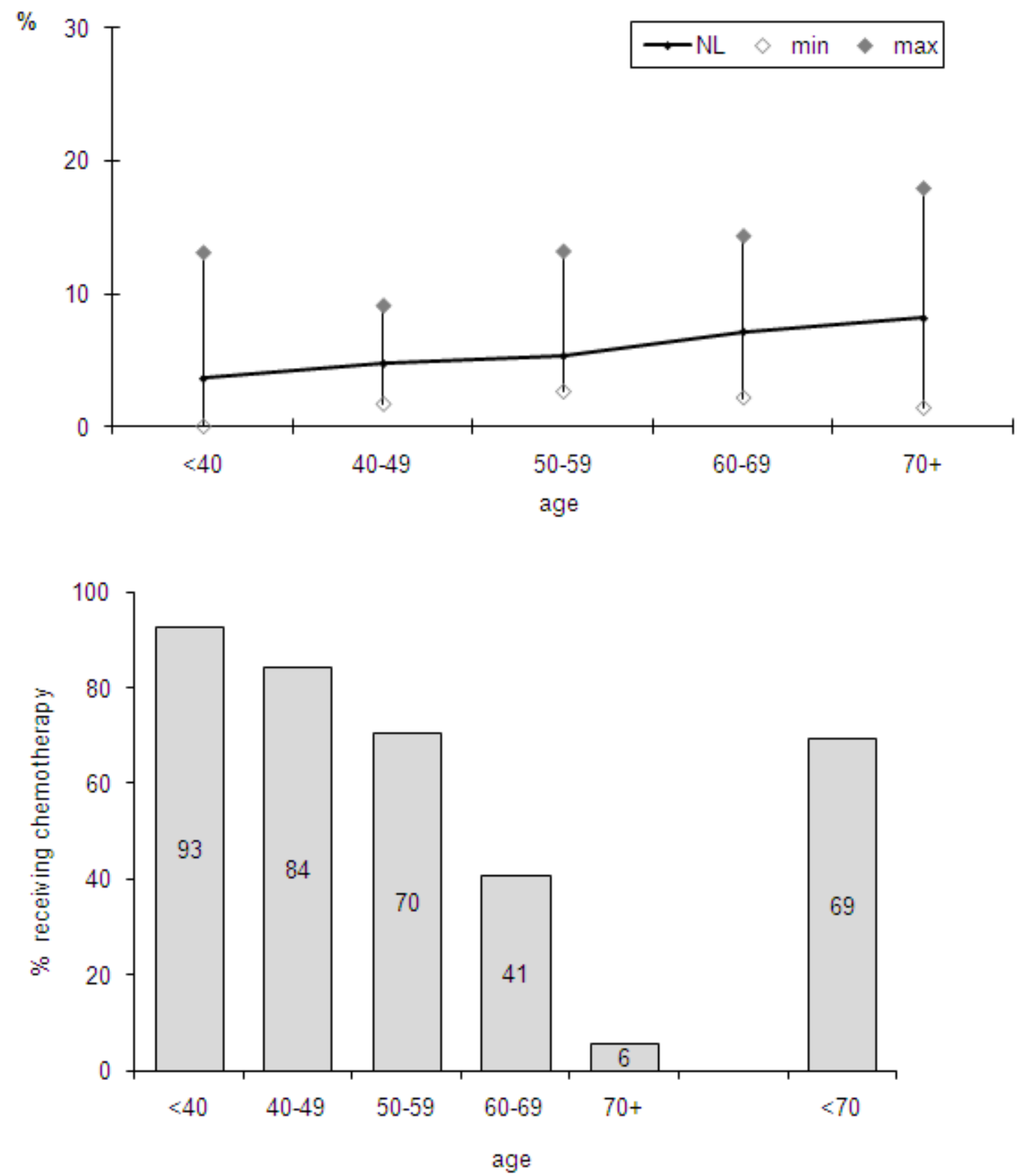


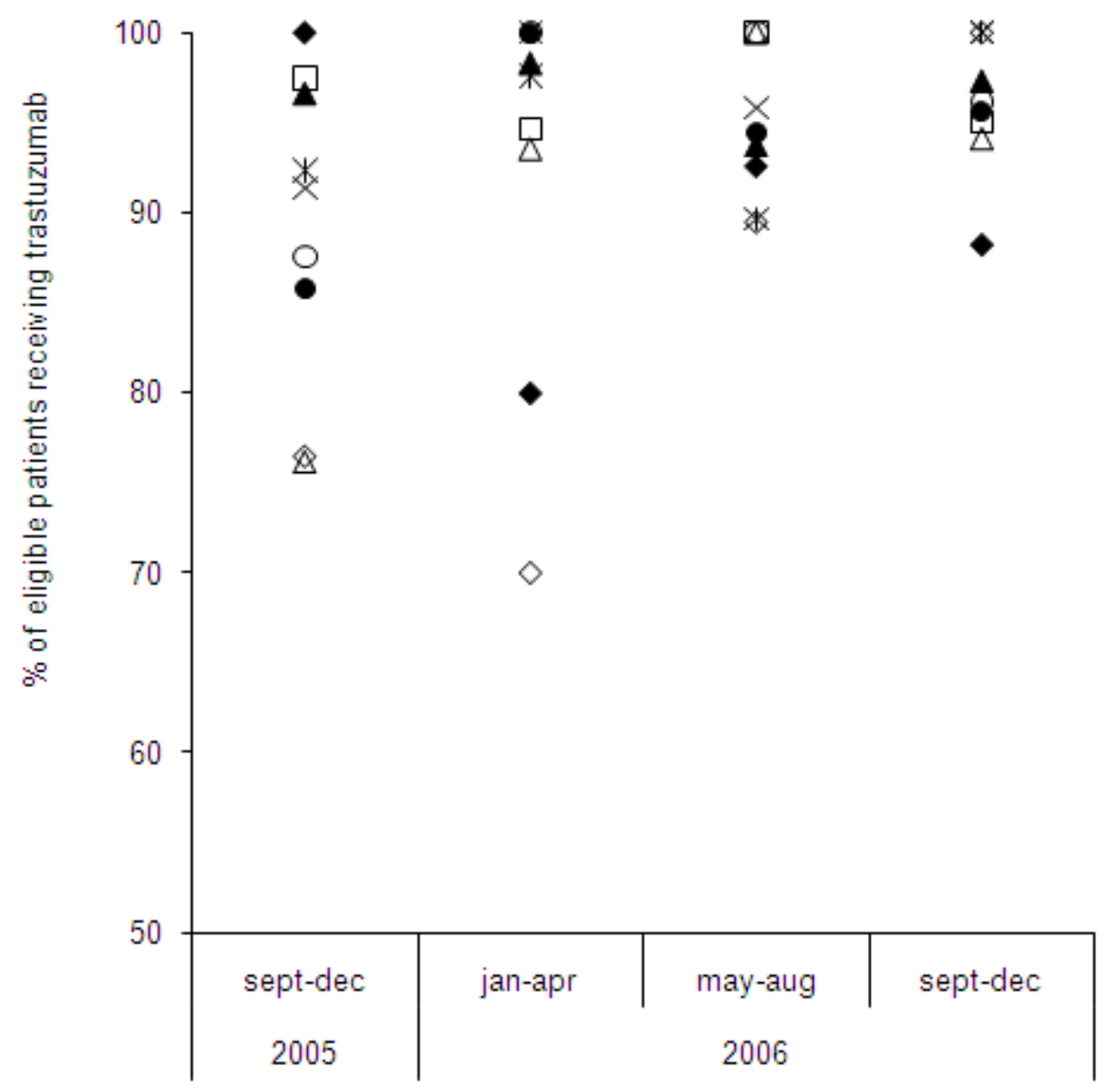

